\title{
Basolateral Amygdala Inactivation Reduces Sexual Motivation in Male Rats during Performance of a T-Maze Task with a Sexual Reward
}

\author{
Marisela Hernández-González ${ }^{1 *}$, Francisco Abelardo Robles Aguirre², \\ Miguel Ángel Guevara1, Gina Lorena Quirarte ${ }^{3}$, \\ Paulina Haro Magallanes ${ }^{1}$ \\ ${ }^{1}$ Instituto de Neurociencias, Universidad de Guadalajara, Guadalajara, Jalisco, México \\ ${ }^{2}$ Centro Universitario del Norte, Universidad de Guadalajara, Colotlán, Jalisco, México \\ ${ }^{3}$ Instituto de Neurobiología, Campus UNAM-UAQ, Juriquilla, Querétaro, México \\ Email: ${ }^{*}$ mariselh@cencar.udg.mx
}

Received 25 March 2014; revised 1 May 2014; accepted 9 May 2014

Copyright (C) 2014 by authors and Scientific Research Publishing Inc.

This work is licensed under the Creative Commons Attribution International License (CC BY). http://creativecommons.org/licenses/by/4.0/

(c) (i) Open Access

\section{Abstract}

This study was aimed to determine the effect of amygdaline inactivation on the sexual motivation of male rats during a T-maze task with a sexual reward. Subjects were chronically implanted with two stainless-steel cannulae that enabled the infusion of tetrodotoxin, a sodium channel blocker, into the left and right basolateral amygdala (BLA). Animals were divided into 3 groups: saline (SS); TTX1 (tetrodotoxin at $2.5 \mathrm{ng}$ ); and TTX2 (tetrodotoxin at $5.0 \mathrm{ng}$ ). To induce a sexually-motivated state, all male rats were allowed to have an intromission with a receptive female before performing the T-maze task, after which their sexual motivation was evaluated during seven trials in which a receptive female was placed in one goal-box of the T-maze, and a non-receptive one in the other. Subjects were allowed an intromission as a sexual reward whenever they reached the goalbox containing the receptive female, but were returned to the start-box if they did not. At the end of the experiment, copulation until ejaculation was permitted. Both doses of TTX increased the time rats required to cross the maze stem during the final trials. In terms of sexual interaction, the high dose of TTX increased more markedly mount, intromission and ejaculation latencies and the number of mounts and intromissions. Overall, these results indicate that the BLA may play an important role in modulating sexual behavior, particularly in maintaining sexual motivation in successive trials in a T-maze task and during sexual interaction per se.

\footnotetext{
"Corresponding author.
}

How to cite this paper: Hernández-González, M., et al. (2014) Basolateral Amygdala Inactivation Reduces Sexual Motivation in Male Rats during Performance of a T-Maze Task with a Sexual Reward. Journal of Behavioral and Brain Science, 4, 223-233. http://dx.doi.org/10.4236/jbbs.2014.45024 


\section{Keywords}

\section{Basolateral Amygdala, Sexual Motivation, Sexual Reward, T-Maze, Tetrodotoxin, Copulation, Rats}

\section{Introduction}

It has been suggested that the amygdala plays an important role in the regulation of several primary motivational states, including sexual-, aggression-, ingestion- and fear-motivated behaviors. The amygdala has been divided into basolateral (BLA), corticomedial (CMA) and central regions [1]-[4], and each one of these sub-regions is involved in the processing of different categories of incoming sensory information. In particular, rich inputs from the neocortex are directed to the BLA, and most olfactory (allocortical) inputs are directed to the CMA, while autonomic regulatory centers in the brainstem are reciprocally connected to the central nuclei [4]. In light of these connections, it has been proposed that the BLA may represent a polymodal, cortical-like area that receives information from the visual, taste, olfactory and auditory cortices [5] [6], while the CMA is a more traditional limbic-like area [6] [7]. It has also been suggested that the BLA may provide a critical area for the motivational processes involved in goal-directed tasks [8]. Through its connections with the orbitofrontal cortex, the BLA has been associated with the assigning of incentive value to relevant stimuli [8]-[17], a fundamental process in generating motivated states. For example, primates with ablation of the BLA show a significant deficit in the associative learning of visual stimuli when presented with a reinforcer from different sensorial modalities [11], while after suffering lesions in the amygdala, monkeys showed impairments in reinforcer devaluation [12] in reversal learning tasks, and in emotional responses to threatening stimuli [13].

Several studies have demonstrated that sex is an efficient incentive in goal-directed tasks [18]-[23]. Beach and Jordan [24] and Whalen et al. [25], for example, have shown that male rats readily learn to scurry through a runway when access to a receptive female is offered as the incentive. For this reason, sexual reward has often been used as an incentive [18]-[21] in characteristic instrumental tasks such as mazes and Skinner boxes [26]-[29]. On the other hand, it is well known that the sexual motivation of male rats changes over the course of their sexual interaction, for it gradually increases during multiple intromissions until ejaculation is reached, after which arousal/motivation levels decrease dramatically (for reviews, see [30] [31]).

Although BLA lesions have not been found to have any disruptive effects on copulation in either male rats [32]-[34] or hamsters [35], it has been suggested that this structure plays an important role in modulating sexual responses. Everitt et al. [36] [37] reported that BLA lesions affected appetitive sexual responses maintained by a secondary visual reinforcer, but not sexual interaction with a female, while Kippin et al. [38] observed an increased Fos-IR activation in the BLA of male rats following exposure to bedding scented with a neutral odor (almond) previously paired with copulation. In a c-fos expression study evaluating the chemoinvestigatory behavior of female mice, Moncho-Bogani et al. [39] demonstrated that the exploration of innately attractive nonvolatile pheromones induced activation of the BLA. Similar results were obtained using a somatosensory cue (an i.p. injection) paired previously with copulation, which induced an increase in glucose utilization in the BLA [40]. Additionally, a few studies suggest the involvement of the BLA in sexual interaction. For example, it has been shown that following 60 stimulations of the left BLA over a 4-week period (long-term kindling), male Long-Evans rats exhibited prolonged latencies in mounting, intromission and ejaculation and lower ejaculation frequencies [41].

Bearing in mind the major role that has been attributed to the BLA in incentive motivation, and considering that copulation is a motivated behavior that depends on the male's ability to process sexual stimuli, the aim of this study was to determine whether inactivation of the BLA in male rats affects the maintenance of sexual motivation during the performance of a T-maze task using a sexual reward (i.e. intromission response).

\section{Methods}

\subsection{Subjects}

The subjects were twenty-four 85-90-day-old male Wistar rats obtained from a colony bred at the Institute of Neurosciences, University of Guadalajara. All male rats were maintained in a room at $22^{\circ} \mathrm{C}-24^{\circ} \mathrm{C}$ with a $12: 12$ $\mathrm{h}$ reversed light/dark cycle (lights on from 2000 to $0800 \mathrm{~h}$ ), and were selected on the basis of their high copula- 
tory performance in preliminary mating tests. Purina Lab Chow and drinking water were available constantly in the home cage, where the animals were housed individually. Estrous was induced in females by s.c. injections of $5 \mu \mathrm{g}$ estradiol valerate and $500 \mu \mathrm{g}$ progesterone per animal, $48 \mathrm{~h}$ and $4 \mathrm{~h}$ before testing, respectively. Animal care and all other procedures involving the rats were approved by our Institutional Animal Care and Use Committee in accordance with NIH specifications.

\subsection{Surgical Procedure}

Prior to the behavioral experiments, the rats were anesthetized with sodium pentobarbital (35 mg/kg) by intraperitoneal injection. The anesthetized subjects were then immobilized in a stereotaxic apparatus and injected around the incision area with Xylocaine. A midline incision was made, after which the skull was dried and cleaned of fascias. Two small holes were drilled bilaterally in the skull posterior to the bregma region, and two permanent stainless steel guide cannulae (23 gauge, $13 \mathrm{~mm}$ ) were placed $2 \mathrm{~mm}$ above the BLA at the following coordinates relative to bregma: antero-posterior: $-2.8 \mathrm{~mm}$; lateral $\pm 4.8 \mathrm{~mm}$ (midline); dorso-ventral: $-6.8 \mathrm{~mm}$ from dura; with the nose bar $-3.30 \mathrm{~mm}$ below the inter-aural lines [42]. The cannulae were fixed to the skull with dental acrylic and stylets were inserted to keep them closed. Another $5 \mathrm{mg}$ of anesthesia were administered near the end of the procedure to minimize any post-surgery pain or discomfort that the rats might experience.

\subsection{Apparatus}

To evaluate the sexual motivation of male rats, a T-maze shaped apparatus constructed of polyurethane-sealed wood was used. The maze consisted of a brown, wooden stem runway with a start-box at one end and two goal-boxes at the other. The start-box $(21 \times 21 \mathrm{~cm})$ was separated from the stem runway by a wooden guillotine door that prevented the rat from moving down the stem runway until training began. The runway was $52 \mathrm{~cm}$ in length and its two arms extended $45 \mathrm{~cm}$ from the point of intersection. All alleys were $9.0 \mathrm{~cm}$ in width and the walls were $10.5 \mathrm{~cm}$ in height. At the end of each arm there was a small closed wooden goal-box $(21 \times 21 \mathrm{~cm})$ with a manual, removable wooden guillotine door with 5 orifices ( $1 \mathrm{~mm}$ radius) through which the male could hear, see and smell the females placed in each box.

\subsection{Pre-Exposure to the T-Maze}

Two hours prior to the start of the sessions, the rats were allowed to walk in the T- maze for a period of 30 min in order to reduce exploratory behavior. They were allowed to move freely inside the T-maze under standard conditions (red light on, temperature of $20^{\circ} \mathrm{C}-25^{\circ} \mathrm{C}$ ).

\subsection{Reversible Inactivation Procedure}

Tetrodotoxin (TTX, Sigma Co.), which reversibly blocks sodium channel conductance, was used to inhibit action potential generation in the BLA during the behavioral tasks. Two doses of TTX and one of saline solution were bilaterally infused in the BLA of different subjects. Infusions were performed bilaterally into the cannulae using injection needles (30 gauge, $12 \mathrm{~mm}$ ) attached to a $10 \mu \mathrm{l}$ Hamilton syringe via polyethylene tubing connected to a KD-Scientific infusion pump. The delivery rate was $0.5 \mu \mathrm{l} / \mathrm{min}$ for $1 \mathrm{~min}$. The injection needles remained in the cannulae for $1 \mathrm{~min}$ following infusion in order to maximize diffusion away from the needle tip and minimize dorsal diffusion. Approximately 40 - 45 min after infusion, each subject was prepared for the T-maze test.

\subsection{Group Assignment}

Subjects were randomly assigned to one of the three groups. Subjects from the group labeled TTX1 (n = 8) received a lower dose of TTX $(2.5 \mathrm{ng} / 0.25 \mu \mathrm{l}$ of saline solution), while a higher dose $(5 \mathrm{ng} / 0.25 \mu \mathrm{l}$ of saline solution) was applied to a second group, labeled TTX2 $(n=8)$. The control group SS $(n=8)$ received only saline solution.

\subsection{Motor Activity Test}

Thirty minutes after TTX infusion, the male rats were placed in a square plastic box (21.6 × 21.6 in) to evaluate 
spontaneous motor activity in the open field test. The floor of the plastic box was divided into 25 squares (each one $4.3 \times 4.3$ in). The interior colour of the box was grey, the dividing lines black and the walls 5.5 in high. The measurement recorded consisted in the number of squares that all four of the rat's legs crossed during the $10 \mathrm{~min}$ test period.

\subsection{T-Maze Motivational Tests}

Before the T-maze task (about 40 min after infusion), each male rat was allowed to have one sexual interaction (only up to the first intromission) with a receptive female inside a transparent acrylic box in order to generate a sexually-motivated state in the males, as reported in other studies [29] [43]. Immediately after intromission, the male rats were placed in the start-box of the T-maze, while a receptive female was placed in the closed goal-box of one arm, and a non-receptive female in the other. The initial position of the receptive female was balanced, so that for half of the subjects, she was located at the end of the right arm and for the other half, she was positioned on the left. Each experimental session consisted of 7 trials, according to previous data which determined that this was the average maximum number of intromissions that male rats can perform without reaching ejaculation [43]. In all trials, if the male selected the maze arm holding the receptive female, the door of the goal-box would open as soon as the subject approached it and one intromission was allowed. But if the arm with the non-receptive female was selected, the rat was given $5 \mathrm{sec}$ to change its decision before being returned to the start-box. The animals were given a 5-min period to cross the T-maze stem and select an arm.

The following parameters were recorded: number of visits to the receptive female; number of visits to the non-receptive female; and number of non-response trials (i.e., when the male failed to select a goal-box within the 5-min period). During the T-maze task, the time that it took the rat to walk through the stem area before arriving at the intersection of the arms was also recorded.

\subsection{Evaluation of Sexual Behavior}

At the end of the T-maze session, the male rats were left in the goal box with the estrous female to copulate until ejaculation. After the post-ejaculatory period, they were placed inside a transparent acrylic box and allowed to have a second sexual interaction up to first intromission (i.e., the second copulatory series). The following copulatory variables were measured: a) mounts (M, mounting with pelvic thrusting but no vaginal penetration); b) mount latency (ML, time from the entry of the receptive female into the observation cage to the first mount); c) intromission (I, mounting with behavioral signs of vaginal penetration); d) intromission latency (IL, time from the entry of the female into the observation cage to first intromission); e) ejaculation (E, mounting with behavioral signs of seminal expulsion); f) ejaculation latency (EL, time from first intromission to the ejaculatory pattern); g) post-ejaculatory interval (PEI, time from the ejaculatory pattern to the first intromission of the second copulatory series); as well as the number of mounts (NM) and intromissions (NI). Each trial was ended upon observing one of the following conditions: 1) a maximum of 15 min with no mounts or intromissions; 2) a maximum of 30 min after first intromission without ejaculation; 3) the first intromission following initial ejaculation; or, 4) a maximum of 15 min after ejaculation with no additional intromissions.

\subsection{Histology}

At the end of the experiment, the animals were deeply anesthetized with sodium pentobarbital. An intracardial infusion of isotonic saline $(0.9 \%)$ followed by a $5.0 \%$ buffered paraformaldehyde solution was used to fix the brain, which was subsequently removed and stored in formalin for at least two weeks. Sections of $50 \mu$ thickness were then sliced using a microtome and stained with cresyl violet. Inspection under a stereoscopic microscope following the stereotaxic coordinates made it possible to reconstruct the path that the cannulae had followed. Only the behavior of those subjects whose cannulae were correctly positioned over the BLA was included in the data analysis.

\subsection{Statistics}

Comparisons of motor activity and male copulatory behaviors were made with a series of one-way ANOVAs for each sexual parameter registered. Statistical analysis of data from the motivational sessions was conducted by means of another series of one-way ANOVAs for the visits to the receptive female, visits to the non-receptive 
females, and non-response trials. Post-hoc analysis was performed with t-Student tests of the copulatory and motivational task variables. The time the rats spent walking through the runway stem was compared with the non-parametric Kruskall-Wallis test on a trial-by-trial basis and a post-hoc analysis with the Mann-Whitney U test. For statistical purposes, non-response trials were defined by a maximum duration of 200 sec. Significance for all tests were set at $\mathrm{p}<0.05$ (two-tailed).

\section{Results}

\subsection{Histology}

In all 24 animals, the tips of the needles were located bilaterally in the BLA between 2.5 and $3.0 \mathrm{~mm}$ posterior to bregma, 4.6 to $5.2 \mathrm{~mm}$ lateral to mid-line, and -8.6 to $-9.0 \mathrm{~mm}$ ventral with respect to the dura (Figure 1 ).

\subsection{Motor Activity Test}

The number of squares that the male rats from the three groups crossed in the open field test previous to the T-maze task was similar (average per group, $\mathrm{SS}=70$, TTX1 $=74.75$, TTX2 $=64.87)(\mathrm{F}=0.32 ; \mathrm{p}=0.73)$.

\subsection{Sexual Motivation Parameters in the T-Maze}

All subjects from the three groups were able to perform all 7 trials in the T-maze task without reaching ejaculation. Statistical analysis revealed variations among groups with respect to the time taken to cross the T-maze during the fourth $(\mathrm{H}=6.48, \mathrm{p}=0.039)$, fifth $(\mathrm{H}=10.81, \mathrm{p}=0.0045)$, sixth $(\mathrm{H}=9.12, \mathrm{p}=0.0105)$ and seventh $(\mathrm{H}=13.94, \mathrm{p}=0.0009)$ trials. Subjects in the TTX1 group showed an increase in the time taken to cross the T-maze as compared to the SS group during the fourth $(U=9.5 ; p=0.02)$, fifth $(U=7.5 ; p=0.01)$, sixth $(U=$ 6.5; $\mathrm{p}=0.007)$ and seventh $(\mathrm{U}=2 ; \mathrm{p}=0.006)$ trials; similarly, the TTX2 group needed more time to walk through the T-maze in the fifth $(U=6.0 ; p=0.0047)$, sixth $(U=9.5 ; p=0.02)$ and seventh $(U=6.0 ; p=0.009)$ trials (Table 1).

With respect to the number of visits to the female, no statistically significant differences were found among groups in the number of visits to the receptive female $(F=0.41 ; \mathrm{p}=0.67$ ) (Figure 2(a)), nor were there differences in relation to the number of visits to the non-receptive female after the subjects in the three groups were compared $(\mathrm{F}=2.33 ; \mathrm{p}=0.15$ ) (Figure 2(b)). Finally, although no significant statistical differences were found ( $\mathrm{F}=1.29 ; \mathrm{p}<0.322$ ), a clear tendency towards an increase in the number of non-response trials was observed in the TTX1 and TTX2 groups as compared to SS (Figure 2(c)). The non-response subjects left the start-box to walk in the stem runway but then returned to that box without showing any interest in exploring the arms of the

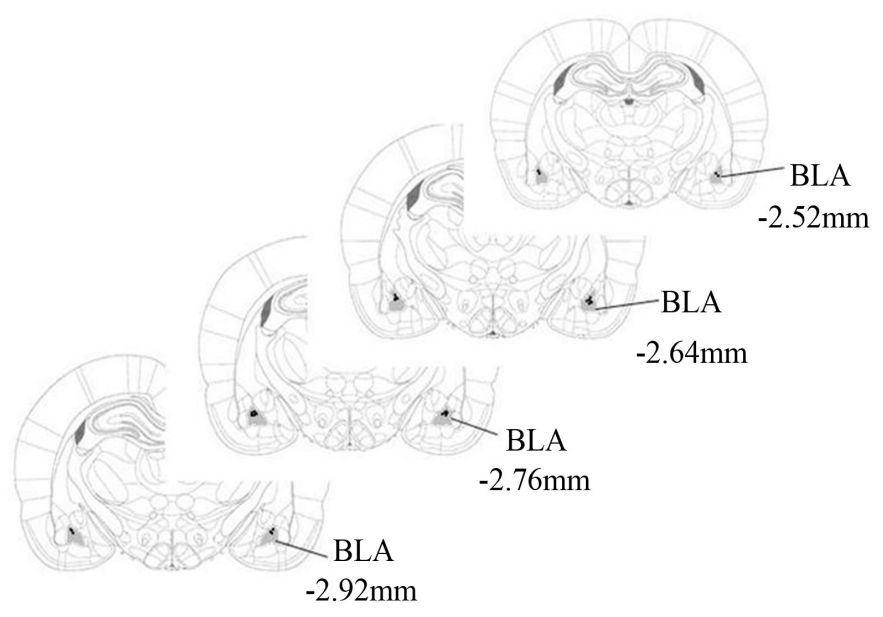

Figure 1. Coronal sections of the rat brain showing the sites where the needle tips were placed in the left and right basolateral amygdala of the subjects $(n=8)$. Distance from bregma for each image is indicated below in millimeters. BLA: Basolateral amygdale. 
Table 1. Medians + interquartile ranges for duration (sec) of the walk in the maze stem shown by the male rats of the different groups $(n=8)$ in each one of the 7 trials during their performance in the T maze.

\begin{tabular}{cccccccc}
\hline \multicolumn{7}{c}{ Trials } \\
Groups & 1 & 2 & 3 & 4 & 5 & 6 & 7 \\
SS & $4.120 \pm 3.8$ & $5.07 \pm 5.57$ & $3.09 \pm 2.17$ & $3.8 \pm 24.65$ & $2.13 \pm 3.6$ & $2.52 \pm 3.64$ & $2.57 \pm 4.75$ \\
TTX1 & $4.64 \pm 13.39$ & $4.40 \pm 16.12$ & $39.2 \pm 196.7$ & $31.2 \pm 193.5^{*}$ & $92.1 \pm 159.6^{*}$ & $48.26 \pm 169.9^{*}$ & $200 \pm 147.05^{*}$ \\
TTX2 & $4.5 \pm 101.4$ & $5.7 \pm 8.6$ & $102.8 \pm 196.8$ & $19.32 \pm 195.3$ & $200 \pm 95.9^{*}$ & $200 \pm 191.9^{*}$ & $53.04 \pm 193.6^{*}$ \\
\hline
\end{tabular}

${ }^{*} \mathrm{p}<0.05$. Mann-Whitney U test significantly higher than control (SS) group.

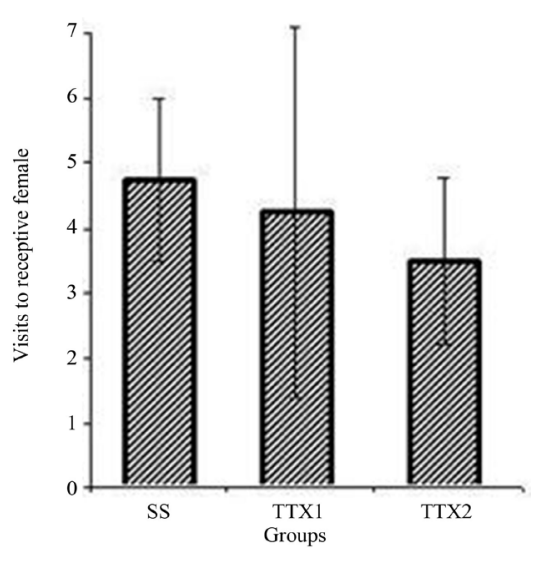

(a)

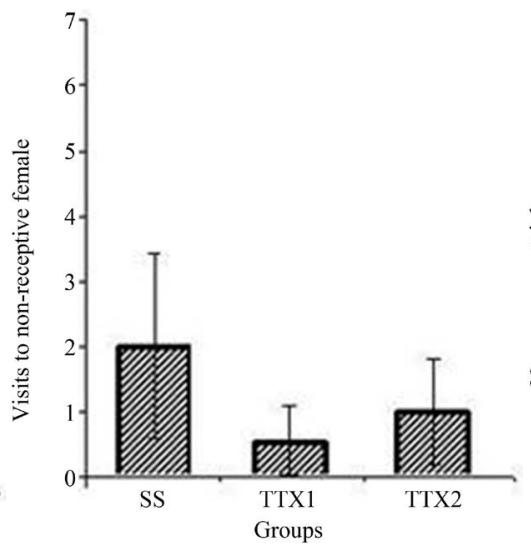

(b)

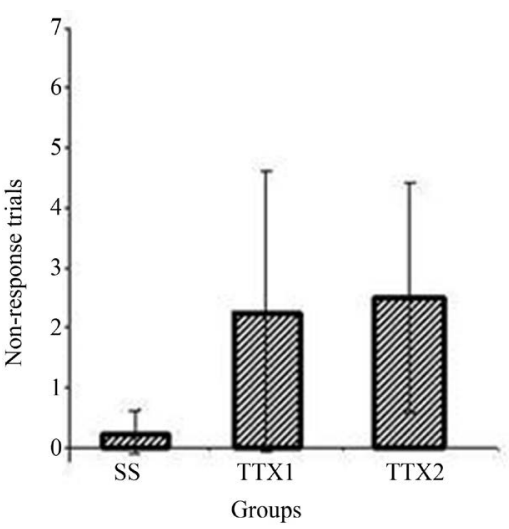

(c)

Figure 2. Mean \pm 2 SE $(n=8)$ of visits to the receptive female $(A)$, visits to the non-receptive female $(B)$, and non-response trials (C), performed by the male rats in each group. SS, Control group treated with saline solution; TTX1, group treated with the lower dose of tetrodotoxin; TTX2, group treated with the higher dose of tetrodotoxin. Comparisons were performed with one-way ANOVAs and t-Student tests.

T-maze and, therefore, without selecting one of the two arms. While those males remained in the stem runway they showed rearing, active sniffing, body grooming and vibrissae movements.

\subsection{Sexual Behavior Parameters}

No significant differences were obtained among the groups for the IL of the first sexual interaction $(\mathrm{F}=2.21$; $\mathrm{p}$ $=0.13$ ) although a tendency was found and further compared with post-hoc tests $(\mathrm{F}=2.21 ; \mathrm{p}=0.13)$. . In the second sexual interaction, no significant differences were observed in EL $(F=1.71 ; p=0.20)$ or PEI $(F=2.98$; $\mathrm{p}=0.07)$; however, significant differences were found in IL $(\mathrm{F}=5.15 ; \mathrm{p}<0.016)$, ML $(\mathrm{F}=3.65 ; \mathrm{p}<0.045)$, NM ( F = 9.95; $\mathrm{p}<0.001)$ and NI $(\mathrm{F}=8.52 ; \mathrm{p}<0.002)$. Post-hoc analysis with the t-Student test showed that the TTX1 group presented a significantly higher number of mounts $(t=3.83$; $<<0.004)$ compared to SS. Meanwhile, TTX2 showed significantly longer IL $(t=2.60 ; p<0.035)$ and ML $(t=2.16$; $p<0.05)$ as well as a higher number of intromissions $(\mathrm{t}=3.57 ; \mathrm{p}<0.004)$ compared to SS (Table 2).

Although no significant differences were detected by the ANOVAs among the three groups regarding the other sexual parameters, tendencies were evaluated through a t-Student post-hoc analysis. Significant differences between the TTX2 and SS groups were obtained, such that the larger doses of TTX increased both the IL ( $\mathrm{t}=$ 2.32; $\mathrm{p}<0.05)$ of the first sexual interaction and the EL $(\mathrm{t}=3.58 ; \mathrm{p}<0.004)$ of the second sexual interaction (Table 2).

\section{Discussion}

This study provides evidence that temporal inactivation of the BLA affected the sexual motivation necessary to perform a T-maze task with a sexual reward, and the sexual motivation involved in sexual interaction per se. Specifically, it was found that TTX induced an increase in the time taken to cross the maze runway to gain access to a receptive female, as well as longer mount, intromission and ejaculation latencies by the male rats 
Table 2. Copulatory parameters recorded during the sexual interactions.

\begin{tabular}{|c|c|c|c|}
\hline & SS & TTX1 & TTX2 \\
\hline \multicolumn{4}{|c|}{ First sexual interaction } \\
\hline IL & $11.87 \pm 3.48$ & $133.12 \pm 70.97$ & $181.25 \pm 72.86^{*}$ \\
\hline \multicolumn{4}{|c|}{ Second sexual interaction } \\
\hline ML & $6.62 \pm 4.27$ & $7.75 \pm 7.44$ & $20 \pm 16.97^{*}$ \\
\hline NM & $5.750 \pm 1.79$ & $22.37 \pm 3.95^{*}$ & $8.37 \pm 2.29$ \\
\hline $\mathrm{IL}$ & $7.25 \pm 1.4$ & $11.25 \pm 3.4$ & $31.75 \pm 9.3^{*}$ \\
\hline NI & $4.87 \pm 0.7$ & $5.75 \pm 0.64$ & $9.37 \pm 0.98^{*}$ \\
\hline EL & $99.12 \pm 55.5$ & $529.25 \pm 200.8$ & $466.75 \pm 87.7^{*}$ \\
\hline PEI & $365.62 \pm 38.4$ & $656.25 \pm 178.2$ & $319.62 \pm 17.3$ \\
\hline
\end{tabular}

${ }^{*} \mathrm{P}<0.05$ t-Student test significantly higher than control (SS) group. ML: Mount latency; IL: Intromission latency; NM: Number of mounts; NI: Number of intromissions; EL: Ejaculation latency; PEI: Postejaculatory interval.

during copulation.

It is well known that when male rats reach ejaculation their sexual motivation decreases. For this reason, in this study it was important to maintain the rats' sexual motivation throughout the tests by allowing them one intromission as a reward whenever they selected the arm holding the receptive female. Therefore, as in a previous study [43], sessions in the T-maze were limited to seven trials in order to impede ejaculation.

TTX was infused into the BLA of the male rats in order to chemically inactivate sodium channel conductance in the neurons located there, so we anticipated a suppression of neuronal activity within a significant extent of this brain structure that would allow us to test for changes in the maintenance of sexual motivation during the seven trials of the sexually-motivated task. As described in other studies, the effect derived by infusing TTX reaches a maximum value after a short period of time (approximately 15 to $20 \mathrm{~min}$ ) at a concentration and volume quite similar to the ones used in this work [44]-[46]. This effect remained in a constant level of inactivation for about 4 hours, with activity returning to the pre-injection level after 12 hours [45] [46]. In this study, TTX was administered 40-45 min before the T-maze task began, thus the BLA should have been temporarily inactivated throughout the session in the T-maze (which could have lasted a maximum of 35 min if all trials were non-response ones) and until the second sexual interaction, according to other studies [46]-[49].

Subjects in the TTX1 and TTX2 groups showed an increase in the time taken to cross the maze runway, which was evident only in the final trials. Considering that this temporal parameter has been used as an index of sexual motivation in tasks with a sexual reward [28] [29], it can be suggested that the inactivation of the BLA induced a gradual decrease of sexual motivation during the sequence of trials in the T maze task. This longer time period required to cross the maze runway was not associated with any motor alteration because, as was demonstrated in a pilot group, the TTX doses used in this study do no alter locomotor activity in any way.

The impairment of the subjects during this motivational task could be a result of the decrease in their ability to detect and contact receptive females in the T-maze task. It has been suggested that the successful performance of sexual behavior by male rats - complex as it is — depends on their ability to distinguish between the cues emitted by sexually-receptive and non-sexually-receptive females [18]-[21] [50]-[52]. These abilities could only be manifested through the processing capacity of specialized neural circuits that allow the stimulation received during sexual interaction to be perceived as rewarding, and the salient stimuli to be associated with positive sexual reinforcement. As mentioned in the Introduction, the BLA and its connections with the orbitofrontal cortex constitute one of the main circuits involved in assigning incentive value to relevant stimuli [11]-[16]. Moreover, it has been suggested that the BLA is a key structure in mediating the encoding of the reward and, more specifically, in establishing the reward-related properties of the outcome [53] [54]. Thus, it is probable that the males under BLA inactivation in this study failed to adequately process the signals emitted by the female, and hence showed a considerable increase in the time required to cross the maze stem, together with a non-preference to visit the receptive female, and a tendency to increase the number of non-response trials. Taken together, these data may suggest that the reversible lesions in the BLA disrupted the "salience" of the sexual stimuli emitted by the receptive female placed in the goal-box of the T-maze, such that the ability of the males to perceive those 
sexual stimuli was gradually reduced.

Sexual motivation during copulatory interaction was also affected as a result of the temporal inactivation of the BLA, especially at the higher dose of TTX. Specifically, the subjects in TTX2 showed prolonged latencies to engage in mounting or intromission behavior, or to achieve ejaculation. This increased latency to begin the sexual interaction was not associated with any motor alteration, as was demonstrated by the rats' adequate performance of motor copulatory responses. Like in this study, similar increased latencies to begin the sexual interaction have been shown after lesions to the prefrontal cortex [55], and after long-term kindling of the BLA [41]; hence, it is probably that males experience some difficulty in identifying the female as a sexual incentive.

In some studies, a longer IL has been related to a deficit in the ability to achieve the erection [56]-[58], while in others it has been associated with decreased sexual arousal [59]. In this study, BLA inactivation increased both ML and IL, possibly suggesting that this alteration of sexual interaction could be a result of the BLA's dysfunction in relation to maintaining sexual motivation, so that during the experimental sessions the sexual motivation of the males remained low and, hence, they failed to adequately begin sexual interaction. Here, we found evidence that the BLA might be involved not only in maintaining the sexual motivation required to perform the T-maze task adequately, but also in the sexual motivation that induces the initiation of motor copulatory patterns and allows male rats to achieve ejaculation.

However, it should be noted that as soon as copulation began in this study the males showed a sexual behavior that was almost normal, and even presented a higher number of mounts and intromissions. Considering that this cerebral structure has also been implicated in sensorimotor integration [60], it is probable that the increase in the number of mounts and intromissions results from a sensory deficit after the BLA lesion that impeded these male rats from achieving the level of sexual activation required to ejaculate.

These results, however, contrast sharply with other reports, which have indicated that BLA lesions have no effect on masculine sexual behavior [32]-[35]. Although it is well known that sexual behavior in rodents is only affected after damage to corticomedial nuclei, it has been proposed that other areas of the amygdala, such as the basolateral nucleus, also play an important role in modulating the sensorial processing of the different stimuli that may participate in generating sexual motivation [36]. Some authors view the projections of the basolateral cell groups as the route by which higher-order sensory information processed in the association cortices is relayed to the hypothalamus to interact with motivational and emotional processes integrated there. Thus, the amygdala may play an important role in the association of stimuli with a variety of biologically-important aspects of events, thus mediating the impact of their reinforcing value [53] [54]. This proposal has been also demonstrated in a sexual context where, for example, BLA lesions affected appetitive sexual responses maintained by a secondary visual reinforcer, but not sexual interaction with a female [36] [37], similarly, following exposure to bedding scented with a neutral odor (almonds) previously paired with copulation, and the exposure to a somatosensory cue (an i.p. injection) paired previously with copulation provoked an increased Fos-IR activation [38] as well as an increase in glucose utilization in the BLA [40]. Moreover, several studies have suggested the involvement of the BLA in modulating sexual behavior, mainly in relation to the sexual arousal associated with rewarding stimuli [38]-[41].

\section{Conclusion}

In summary, these findings indicate that a functionally-intact BLA seems to be critical for maintaining sexual motivation during successive trials in a T-maze task with intromission as the sexual reward, and also for the initiation of sexual behavior. There are, however, various points that should be considered: first, we were unable to discern whether the neuronal activity inhibited by TTX corresponded to that of populations of output neurons in the BLA, or to that of passing fibers from other areas, a matter that remains unclear. Additionally, no one has yet determined to what extent performance in the T-maze task affected the second sexual interaction that subjects were allowed, nor do we know conclusively whether the higher frequency of mounts and intromissions resulted from a sensorial deficit that impeded these male rats from reaching the threshold of sexual activation required to achieve ejaculation. Thus, additional research is required to evaluate more precisely the effect of BLA inactivation on male rat copulatory interaction after TTX administration.

\section{References}

[1] McDonald, A. (2003) Is There an Amygdala and How Far Does It Extend? An Anatomical Perspective. Annual NY 
Academy of Science, 985, 1-21. http://dx.doi.org/10.1111/j.1749-6632.2003.tb07067.x

[2] Pitkänen, A. (2000) Connectivity of the Rat Amygdaloid Complex. In: Aggleton, J.P., Ed., The Amygdala, Oxford University Press, New York, 31-115.

[3] Gloor, P. (1997) The Amygdaloid System. In: Gloor, P., Ed., The Temporal Lobe and Limbic System, Oxford University Press, New York, 591-721.

[4] Price, J.L., Russchen, E.T. and Amaral, D.G. (1987) The Amygdaloid Complex. In: Björklund, A., Hökfelt, T. and Swanson, L.W., Eds., Handbook of Chemical Neuroanatomy, Volume 5, Integrated systems of the CNS, Part 1, Elsevier, Amsterdam, 279-388.

[5] Alheid, G.F. and Heimer, L. (1988) New Perspectives in Basal Forebrain Organization of Special Relevance for Neuropsychiatric Disorders: The Striatopalidal, Amygdaloid, and Corticopetal Components of Substantia Innominata. Neuroscience, 27, 1-39. http://dx.doi.org/10.1016/0306-4522(88)90217-5

[6] McDonald, A. (1998) Cortical Pathways to the Mammalian Amygdala. Progress in Neurobiology, 55, $257-332$. http://dx.doi.org/10.1016/S0301-0082(98)00003-3

[7] Swanson, L.W. and Petrovich, G.D. (1998) What Is the Amygdala? Trends in Neuroscience, 21, 323-333. http://dx.doi.org/10.1016/S0166-2236(98)01265-X

[8] Cardinal, R.N., Parkinson, J.A., Hall, J. and Everitt, B.J. (2002) Emotion and Motivation: The Role of the Amygdala, Ventral Striatum and Prefrontal Cortex. Neuroscience Biobehavioral Review, 26, 321-352. http://dx.doi.org/10.1016/S0149-7634(02)00007-6

[9] G. Schoenbaum, Chiba, A. and Gallagher, M. (1998) Orbitofrontal Cortex and Basolateral Amygdala Encode Expected Outcomes during Learning. Nature Neuroscience, 1, 155-159. http://dx.doi.org/10.1038/407

[10] Hatfield, T., Han, J., Conley, M., Gallagher, M. and Holland, P. (1997) Neurotoxic Lesions of Basolateral, But Not Central, Amygdala Interfere with Pavlovian Second-Order Conditioning and Reinforce Devaluation Effects. The Journal of Neuroscience, 17, 6011-6020.

[11] Gaffan, D. and Murray, A.E. (1990) Amygdalar Interaction with the Mediodorsal Nucleus of the Thalamus and the Ventro-Medial Prefrontal Cortex in Stimulus-Reward Associative Learning in the Monkey. The Journal of Neuroscience, 10, 3479-3493.

[12] Izquierdo, A. and Murray, E.A. (2004) Combined Unilateral Lesions of the Amygdala and Orbital Prefrontal Cortex Impair Affective Processing in Rhesus Monkeys. Journal of Neurophysiology, 91, 2023-2039. http://dx.doi.org/10.1152/jn.00968.2003

[13] Baxter, M.G., Parker, A., Lindner, C.C., Izquierdo, A.D. and Murray, E.A. (2000) Control of Response Selection by Reinforcer Values Requires Interaction of Amygdala and Orbitofrontal Cortex. The Journal of Neuroscience, 20, 43114319.

[14] Schoenbaum, G., Chiba, A. and Gallagher, M. (2000) Changes in Functional Connectivity in Orbitofrontal Cortex and Basolateral Amygdala during Learning and Reversal Training. The Journal of Neuroscience, 20, 5179-5189.

[15] Schoenbaum, G., Setlow, B., Nugent, S., Saddoris, M. and Gallagher, M. (2003) Lesions of Orbitofrontal Cortex and Basolateral Amygdala Complex Disrupt Acquisition of Odor-Guided Discriminations and Reversals. Learning and Memory, 10, 129-140. http://dx.doi.org/10.1101/lm.55203

[16] Schoenbaum, G., Setlow, B., Saddoris, M. and Gallagher, M. (2003) Encoding Predicted Outcome and Acquired Value in Orbitofrontal Cortex during Cue Sampling Depends upon Input from Basolateral Amygdala. Neuron, 39, 855-867. http://dx.doi.org/10.1016/S0896-6273(03)00474-4

[17] Baxter, M.G. and Murray, E.A. (2002) The Amygdala and Reward. Nature Reviews Neuroscience, 3, 563-573. http://dx.doi.org/10.1038/nrn875

[18] Sheffield, F.D., Wulff, J.J., and Backer, R.R. (1951) Reward Value of Copulation without Sexual Drive Reduction. Journal of Comparative and Physiological Psychology, 44, 3-8. http://dx.doi.org/10.1037/h0060074

[19] Sheffield, F.D., Roby, T.B. and Campbell, B.A. (1954) Drive Reduction versus Consummatory Behavior as Determinants of Reinforcement. Journal of Comparative and Physiological Psychology, 47, 349-354. http://dx.doi.org/10.1037/h0054471

[20] Denniston, R.H. (1954) Quantification and Comparation of Sex Drives under Various Conditions in Terms of Learned Responses. Journal of Comparative and Physiological Psychology, 47, 437-440. http://dx.doi.org/10.1037/h0057942

[21] Kagan, J. (1955) Differential Reward Value of Incomplete and Complete Sexual Behaviour. Journal of Comparative and Physiological Psychology, 48, 59-64. http://dx.doi.org/10.1037/h0043461

[22] Everitt, B.J., Fray, P., Kostarczyk, E., Taylor, S. and Stacey, P. (1987) Studies of Instrumental Behavior with Sexual Reinforcement in Male Rats (Rattus norvegicus): I. Control by Brief Visual Stimuli Paired with a Receptive Female. Journal of Comparative Psychology, 101, 395-406. http://dx.doi.org/10.1037/0735-7036.101.4.395 
[23] Jowaisas, D., Taylor, J., Dewsbury, D.A. and Malagodi, E.F. (1971) Copulatory Behavior of Male Rats under an Imposed Operant Requirement. Psychonomic Science, 25, 287-290. http://dx.doi.org/10.3758/BF03335879

[24] Beach, F.A. and Jordan, L. (1956) Effects of Sexual Reinforcement upon the Performance of Male Rats in a Straight Runway. Journal of Comparative and Physiological Psychology, 49, 105-110. http://dx.doi.org/10.1037/h0046471

[25] Whalen, R.E., Beach, F.A. and Kuehn, R.E. (1961) Effects of Exogenous Androgen on Sexually Responsive and Unresponsive Male Rats. Endocrinology, 68, 373-380. http://dx.doi.org/10.1210/endo-69-2-373

[26] Everitt, B.J. and Stacey, P. (1987) Studies of Instrumental Behavior with Sexual Reinforcement in Male Rats (Rattus norvegicus): II. Effects of Preoptic Area Lesions, Castration, and Testosterone. Journal of Comparative Psychology, 101, 407-419. http://dx.doi.org/10.1037/0735-7036.101.4.407

[27] Hetta, J. and Meyerson, B.J. (1978) Sexual Motivation in the Male Rat: A Methodological Study of Sex-Specific Orientation and the Effects of Gonadal Hormones. Acta Physiologica Scandinavica Supplementum, 453, 1-67.

[28] López, H.H. and Ettenberg, A. (2001) Dopamine Antagonism Attenuates the Unconditioned Incentive Value of Estrous Female Cues. Pharmacology and Biochemical Behavior, 68, 411-416. http://dx.doi.org/10.1016/S0091-3057(00)00472-X

[29] Hernández-González, M., Prieto-Beracoechea, C.A., Arteaga-Silva, M. and Guevara, M.A. (2007) Different Functionality of the Medial and Orbital Prefrontal Cortex during a Sexually Motivated Task in Rats. Physiology \& Behavior, 90, 450-458. http://dx.doi.org/10.1016/j.physbeh.2006.10.006

[30] Sachs, B.D. and Barfield, R.J. (1976) Functional Analysis of Masculine Copulatory Behavior in the Rat. In: Hinde, R. A., Shaw, E. and Beer, C., Eds., Advances in the Study of Behaviour, Vol. 7, Academic Press, New York, 91-154.

[31] Kurtz, R. and Adler, N. (1973) Electrophysiological Correlates of Copulatory Behavior in the Male Rat: Evidence for a Sexual Inhibitory Process. Journal of Comparative and Physiological Psychology, 84, 225-239. http://dx.doi.org/10.1037/h0035265

[32] Harris, V.S. and Sachs, B.D. (1975) Copulatory Behavior in Male Rats Following Amygdaloid Lesions. Brain Research, 86, 514-518. http://dx.doi.org/10.1016/0006-8993(75)90906-3

[33] Kondo, S. (1992) Lesions of the Medial Amygdala Produce Severe Impairment of Copulatory Behavior in Sexually Inexperienced Male Rats. Physiology \& Behavior, 51, 939-943. http://dx.doi.org/10.1016/0031-9384(92)90074-C

[34] McGregor, A. and Herbert, J. (1992) Differential Effects of Excitotoxic Basolateral and Corticomedial Lesions of the Amygdala on the Behavioural and Endocrine Responses to Either Sexual or Aggression-Promoting Stimuli in the Male Rat. Brain Research, 574, 9-20. http://dx.doi.org/10.1016/0006-8993(92)90793-9

[35] Lehman, M.N. and Winans, S.S. (1982) Vomeronasal and Olfactory Pathways to the Amygdala Controlling Male Hamster Sexual Behavior: Autoradiographic and Behavioral Analyses. Brain Research, 240, 27-41. http://dx.doi.org/10.1016/0006-8993(82)90641-2

[36] Everitt, B.J., Cador, M. and Robbins, T.W. (1989) Interactions between the Amygdala and Ventral Striatum in Stimulus-Reward Associations: Studies Using a Second-Order Schedule of Sexual Reinforcement. Neuroscience, 30, 63-75. http://dx.doi.org/10.1016/0306-4522(89)90353-9

[37] Everitt, B.J., Cardinal, R.N., Parkinson, J.A. and Robbins, T.W. (2003) Appetitive Behavior: Impact of Amygdala Dependent Mechanisms of Emotional Learning. Annual New York Academy of Science, 985, 233-250.

[38] Kippin, T.E., Cain, S.W. and Pfaus, J.G. (2003) Estrous Odors and Sexually Conditioned Neutral Odors Activate Separate Neural Pathways in the Male Rat. Neuroscience, 117, 971-979. http://dx.doi.org/10.1016/S0306-4522(02)00972-7

[39] Moncho-Bogani, J., Martinez-Garcia, F., Novejarque, A. and Lanuza, E. (2005) Attraction to Sexual Pheromones and Associated Odorants in Female Mice Involves Activation of the Reward System and Basolateral Amygdala. European Journal of Neuroscience, 21, 2186-2189. http://dx.doi.org/10.1111/j.1460-9568.2005.04036.X

[40] De Jonge, F.H., Tonnaer, J.A., Van Leeuwe, H., Tielemans, A.J., Louwerse, A.L. and Van de Poll, N.E. (1992) Cerebral Glucose Utilization during Conditioned Sexual Arousal. Physiology and Behavior, 52, 1009-1013. http://dx.doi.org/10.1016/0031-9384(92)90383-D

[41] Magyar, O., Hill, M.N., Pinel, J.P. and Gorzalka, B.B. (2005) Long-Term Kindling of the Basolateral Amygdala Impairs Copulatory Behavior in Male Rats. Neuroscience Letters, 390, 162-165. http://dx.doi.org/10.1016/j.neulet.2005.08.012

[42] Paxinos, G. and Watson, C. (1997) The Rat Brain in Stereotaxic Coordinates. Academic Press, New York.

[43] Guevara, M.A., Robles-Aguirre, F.A., Quirarte, G.L. and Hernández-González, M. (2009) Orbitofrontal Cortex Inactivation Impairs Early Reversal Learning in Male Rats during a Sexually Motivated Task. International Journal of Psychology and Psychological Therapy, 9, 141-160.

[44] Bielawska, E. and Roldan, G. (1996) Ipsilateral Connections between the Gustatory Cortex, Amygdala and Parabrachi- 
al Nucleus are Necessary for Acquisition and Retrieval of Conditioned Taste Aversion in Rats. Behavioural Brain Research, 81, 25-31. http://dx.doi.org/10.1016/S0166-4328(96)00039-3

[45] Boehnke, S. and Rasmusson, D. (2001) Time Course and Effective Spread of Lidocaine and Tetrodotoxin Delivered via Microdialysis: An Electrophysiological Study in Cerebral Cortex. Journal of Neuroscience Methods, 105, 133-141. http://dx.doi.org/10.1016/S0165-0270(00)00348-4

[46] Ali-Vafaei, A. and Rashidy-Pour, A. (2004) Reversible Lesion of the Rat's Orbitofrontal Cortex Interferes with Hippocampus-Dependent Spatial Memory. Behavioral Brain Research, 149, 61-68. http://dx.doi.org/10.1016/S0166-4328(03)00209-2

[47] Kilpatrick, L. and Cahill, L. (2003) Modulation of Memory Consolidation for Olfactory Learning by Reversible Inactivation of the Basolateral Amygdala. Behavioral Neuroscience, 117, 184-188. http://dx.doi.org/10.1037/0735-7044.117.1.184

[48] Quiroz, C., Martínez, I., Quirarte, G.L., Morales, T., Díaz-Cintra, S. and Prado-Alcalá, R. (2003) Enhanced Inhibitory Avoidance Learning Prevents the Memory-Impairing Effects of Posttraining Hippocampal Inactivation. Experimental Brain Research, 221, 400-422. http://dx.doi.org/10.1007/s00221-003-1704-1

[49] Lorenzini, A., Baldi, E., Bucherelli, C., Sacchetti, B. and Tassoni, G. (1997) Analysis of Mnemonic Processing by Means of Totally Reversible Inactivations. Brain Research Protocols, 1, 391-398. http://dx.doi.org/10.1016/S1385-299X(97)00017-2

[50] Ågmo, A. (1999) Sexual Motivation-An Inquiry into Events Determining the Ocurrence of Sexual Behavior. Behavioural Brain Research, 105, 129-150. http://dx.doi.org/10.1016/S0166-4328(99)00088-1

[51] Ågmo, A. (2002) Copulation-Contingent Aversive Conditioning and Sexual Incentive Motivation in Male Rats: Evidence for a Two-Stage Process of Sexual Behavior. Physiology \& Behavior, 77, 425-435. http://dx.doi.org/10.1016/S0031-9384(02)00874-0

[52] Pfaff, D.W. and Ågmo, A. (2002) Reproductive Motivation. In: Gakkistel, R. and Pashler, H., Eds., Steven’s Handbook of Experimental Psychology: Learning, Motivation and Emotion, Vol. 3, John Wiley and Sons, New York, 709-736. http://dx.doi.org/10.1002/0471214426.pas0317

[53] Balleine, B.W., Killcross, S. and Dickinson, A. (2003) The Effect of Lesions of the Basolateral Amygdala on Instrumental Conditioning. The Journal of Neuroscience, 23, 666-675.

[54] Balleine, B.W. and Dickinson, A. (1998) Goal-Directed Instrumental Action: Contingency and Incentive Learning and Their Cortical Substrates. Neuropharmacology, 37, 407-419. http://dx.doi.org/10.1016/S0028-3908(98)00033-1

[55] Ågmo, A., Villalpando, A., Picker, Z. and Fernández, H. (1995) Lesions of the Medial Prefrontal Cortex and Sexual Behavior in the Male Rat. Brain Research, 9, 177-186. http://dx.doi.org/10.1016/0006-8993(95)00852-H

[56] Pfaus, J.G. (1999) Neurobiology of Sexual Behavior. Current Opinion in Neurobiology, 9, 751-758. http://dx.doi.org/10.1016/S0959-4388(99)00034-3

[57] Hull, E.M., Meisel, R.L. and Sachs B.D. (2002) Male Sexual Behavior. In: Pfaff, D.W., Arnold, A.P., Etgen, A.M., Fahrbach, S.E. and Rubin, R.T., Eds., Hormones, Brain and Behavior, Academic Press, Waltham, 3-137. http://dx.doi.org/10.1016/B978-012532104-4/50003-2

[58] Sachs, B.D. (2000) Contextual Approaches to the Physiology and Classification of Erectile Function, Erectile Dysfunction, and Sexual Arousal. Neuroscience \& Biobehavioral Review, 24, 541-560. http://dx.doi.org/10.1016/S0149-7634(00)00022-1

[59] Pfaus, J.G., Kipping, T.E. and Coria-Avila, G. (2003) What Can Animal Models Tell Us about Human Sexual Response? Annual Review of Sex Research, 14, 1-63.

[60] Turner, B.H. (1973) Sensorimotor Syndrome Produced by Lesions of the Amygdala and Lateral Hypothalamus. Journal of Comparative and Physiological Psychology, 82, 37-47. http://dx.doi.org/10.1037/h0033803 